Article

\title{
Whole Genome Sequencing and Annotation of Naematelia aurantialba (Basidiomycota, Edible-Medicinal Fungi)
}

\author{
Tao Sun ${ }^{1}$, Yixuan Zhang ${ }^{1}$, Hao Jiang ${ }^{1}$, Kai Yang ${ }^{1}$, Shiyu Wang ${ }^{1}$, Rui Wang ${ }^{1}$, Sha Li ${ }^{1}$, Peng Lei ${ }^{1, *}$, Hong Xu ${ }^{1, *}$, \\ Yibin Qiu ${ }^{2}$ and Dafeng Sun ${ }^{3}$
}

1 State Key Laboratory of Materials-Oriented Chemical Engineering, College of Food Science and Light Industry, Nanjing Tech University, Nanjing 211816, China; sun-tao@njtech.edu.cn (T.S.); zhangyixuan@njtech.edu.cn (Y.Z.); jianghao@njtech.edu.cn (H.J.); 201961119005@njtech.edu.cn (K.Y.); 201921019081@njtech.edu.cn (S.W.); ruiwang2013@njtech.edu.cn (R.W.); lisha@njtech.edu.cn (S.L.)

2 College of Light Industry and Food Engineering, Nanjing Forestry University, Nanjing 210037, China; qyb@njfu.edu.cn

3 Kunming Edible Fungi Institute of All China Federation of Supply and Marketing Cooperatives, Kunming 650032, China; sdafeng@163.com

* Correspondence: lei-peng@njtech.edu.cn (P.L.); xuh@njtech.edu.cn (H.X.); Tel.: +86-187-6168-1790 (P.L.); Tel./Fax: +86-25-5813-9433 (H.X.)

check for updates

Citation: Sun, T.; Zhang, Y.; Jiang, H.; Yang, K.; Wang, S.; Wang, R.; Li, S.; Lei, P.; Xu, H.; Qiu, Y.; et al. Whole Genome Sequencing and Annotation of Naematelia aurantialba

(Basidiomycota, Edible-Medicinal Fungi). J. Fungi 2022, 8, 6. https:/ / doi.org/10.3390/jof8010006

Academic Editors: Lucïa Ramírez and Antonio Pisabarro

Received: 11 November 2021 Accepted: 21 December 2021 Published: 22 December 2021

Publisher's Note: MDPI stays neutral with regard to jurisdictional claims in published maps and institutional affiliations.

Copyright: (C) 2021 by the authors. Licensee MDPI, Basel, Switzerland. This article is an open access article distributed under the terms and conditions of the Creative Commons Attribution (CC BY) license (https:// creativecommons.org/licenses/by/ $4.0 /)$.

\begin{abstract}
Naematelia aurantialba is a rare edible fungus with both nutritional and medicinal values and especially rich in bioactive polysaccharides. However, due to the lack of genomic information, researches on the mining of active compounds, artificial breeding and cultivation, genetics, and molecular biology are limited. To facilitate the medicinal and food applications of N. aurantialba, we sequenced and analyzed the whole genome of $N$. aurantialba for the first time. The 21-Mb genome contained 15 contigs, and a total of 5860 protein-coding genes were predicted. The genome sequence shows that 296 genes are related to polysaccharide synthesis, including 15 genes related to nucleosideactivated sugar synthesis and 11 genes related to glucan synthesis. The genome also contains genes and gene clusters for the synthesis of other active substances, including terpenoids, unsaturated fatty acids, and bioactive proteins. In addition, it was also found that N. aurantialba was more closely related to Naematelia encephala than to Tremella fuciformis. In short, this study provides a reference for molecular cognition of N. aurantialba and related researches.
\end{abstract}

Keywords: Naematelia aurantialba; whole-genome sequencing; functional annotation; secondary metabolism; polysaccharides

\section{Introduction}

Mushrooms are widely distributed food and medicine resource on Earth and have excellent nutritional and medicinal value [1,2]. The mushrooms are considered as superfoods, which are among the world's healthiest foods, and approximately $50 \%$ of edible mushrooms are recognized as functional foods [3]. Naematelia aurantialba syn. Tremella aurantialba, also known as Jin'er, an edible and medicinal fungus distributed in China, is widely popular because of its unique flavor and high nutritional value in its fruiting bodies [4]. Previous studies have reported that the main medicinal functions of N. aurantialba include antioxidant, anti-inflammatory, anti-tumor, and immunomodulatory effects, for which polysaccharides, active proteins, and terpenoids are responsible [5-9]. Polysaccharides are recognized as one of the most active compounds in $N$. aurantialba, which has a total carbohydrate content of $74.11 \%$, including a $40 \%$ content of water-soluble polysaccharides [7]. In addition, $N$. aurantialba is a fungus containing phenolic acids and flavonoids, which has antioxidant effects [10]. The fruiting body of N. aurantialba grows on rotten wood, which has the ability to degrade lignocellulose because it is rich in carbohydrate-active enzymes (CAZymes) [11,12]. It is also possible that $N$. aurantialba has these degrading 
enzymes, and the activities of these enzymes may be beneficial to biomass utilization and organic pollutant degradation.

With the rapid development of DNA sequencing technology and gene-editing technology, strengthening the polysaccharide synthetic pathway through metabolic engineering strategies has become a possible way to improve the yield of mushroom polysaccharides, which can lead to the industrial production of polysaccharides in the future [13-16]. However, there have been no reports on improving the production of N. aurantialba polysaccharides by genetic modification techniques. The reason is mostly due to the lack of relevant genome-wide information, which limits the development of genetic manipulation methods. In addition, the development of genome sequencing technologies has provided new insights into active compound mining, variety breeding, high-yield cultivation, and population genetics [17-21]. The taxonomic boundaries between mushrooms are blurred, and fungal names have long been controversial, which has led to slow development of good quality varieties of mushrooms and thus difficulties in achieving large-scale production [22]

The medicinally valuable sang'huang recorded in the ancient book of traditional Chinese medicine has previously been considered as Sanghuangporus baumii and Sanghuangporus vaninii; yet, Ying et al. clarified its taxonomic status by comparative genomic analysis and named it sanghuangporus sangguang [22,23]. The golden needling mushroom in East Asia has been reported as Asian Flammulina velutipes or Flammulina velutipes var. filiformis [24]. However, the phylogenetic results based on multiple gene markers and morphological comparisons suggest that so-called F. velutipes in East Asia, unlike the European winter mushroom $F$. velutipes, should be treated as a separate species, namely F. filiformis [25]. A similar problem was reported for Jin'er, which was previously reported as Tremella mesenterica [26]. Bandoni R.J. studied the morphological features of Jin'er and named it T. aurantialba [11]. Until 2015, Liu et al. investigated the phylogenetic relationship of Tremellomycetes by phylogenetic trees constructed by seven gene sequences, eventually naming them N. aurantialba [27]. Therefore, it is necessary to further clarify the taxonomic status of $N$. aurantialba genetically from the population level.

In recent years, the genomes of some basidiomycetes have been obtained, including Agaricus bisporus [28], Auricularia heimuer [17], Coprinopsis cinerea [29], G. lucidum [30], Hericium erinaceus [21], Lentinula edodes [31], Naematelia encephala [32], Tremella fuciformis [33], and T. mesenterica [34]. The availability of these increased genome sequences has promoted research on gene diversity and the identification of genes involved in the biosynthesis of secondary metabolites through genome mining. Although N. aurantialba has many important characteristics, there are only about 13 available nucleotide sequences for N. aurantialba in the National Center for Biotechnology Information (NCBI) database, most of which are used for phylogenetic analysis. Therefore, the current genetic sequence resources are not enough to reveal the pharmacological mechanism of N. aurantialba at the molecular level.

Therefore, in this study, we aimed to introduce the whole genome sequence of N. aurantialba NX-20 and to elucidate the its genome through comparison with the genomes of 18 basidiomycetes. We also aimed to investigate functional annotations (Gene Ontology (GO), Kyoto Encyclopedia of Genes and Genomes (KEGG), Clusters of Orthologous Groups (KOG), Transporter Classification Database (TCDB), etc.) to predict the genes or gene clusters involved in the biosynthesis of polysaccharides and other secondary metabolites.

\section{Materials and Methods}

\subsection{Fungal Strains and Strain Culture}

The fruiting bodies of N. aurantialba were collected from Kunming, Yunnan Province, China (Figure 1). A single spore strain was obtained from the fruiting body by the spore ejection method, and the strain was identified as N. aurantialba, which we named N. aurantialba NX-20 [35]. At present, this strain has been preserved in the China General Microbiological Culture Collection Center (CGMCC 18588). To obtain sufficient cell amounts for genomic 
DNA extraction, N. aurantialba NX-20 was inoculated into potato dextrose broth medium and grown at $25^{\circ} \mathrm{C}$ with constant shaking (200 rpm) for $3 \mathrm{~d}$ [35].

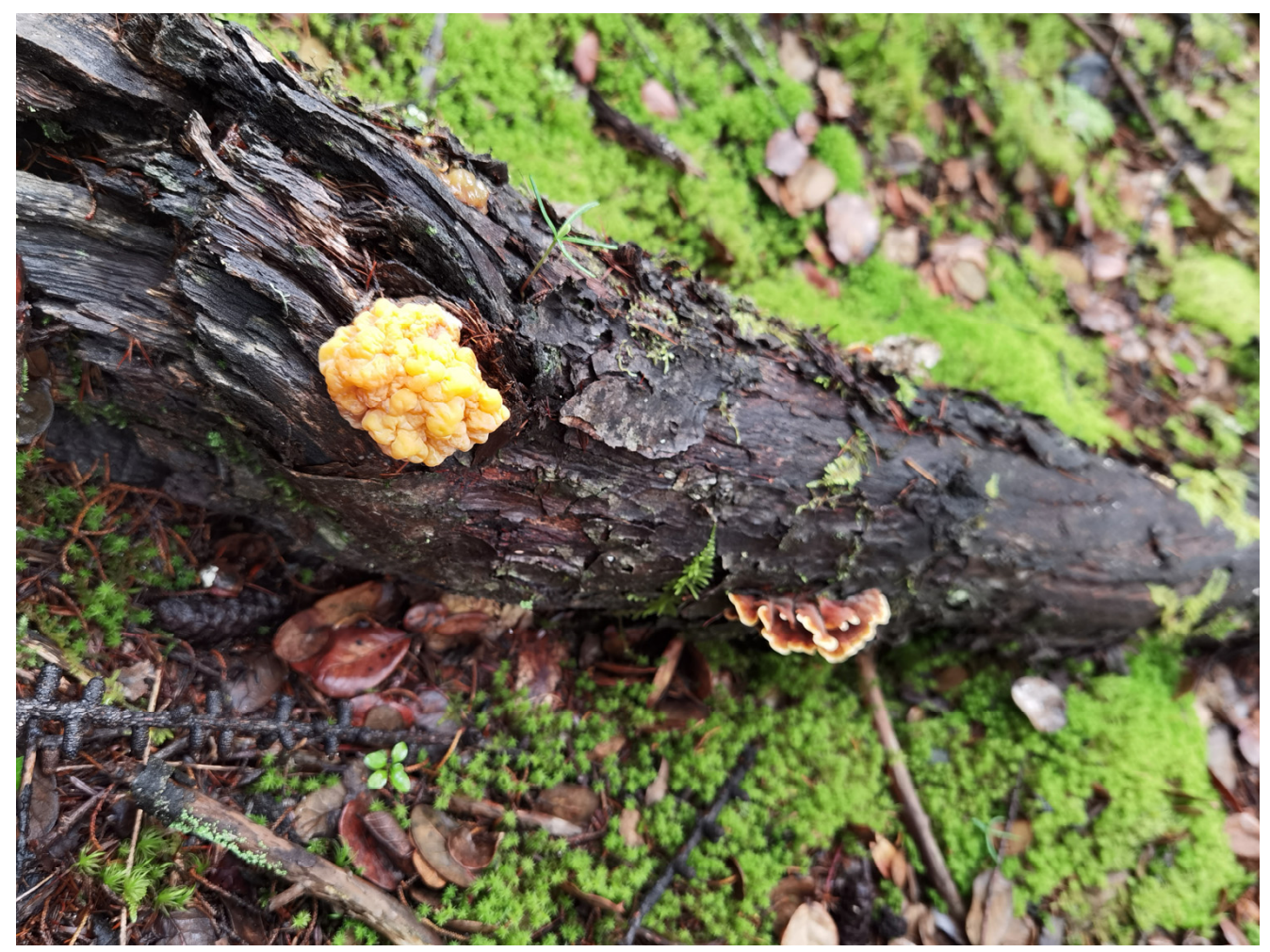

Figure 1. Fruiting bodies of N. aurantialba.

\subsection{Extraction of Genome DNA}

After fermentation, the spore cells were collected by centrifugation at $8000 \times g$ for $5 \mathrm{~min}$, and sterile water (three rinses) was used to remove the medium and metabolites attached to the spore cell surface. The sodium dodecyl sulfate (SDS) method was used to extract the genomic DNA, and agarose gel electrophoresis was performed to check its integrity [23].

\subsection{De Novo Sequencing and Genome Assembly}

\subsubsection{De Novo Sequencing}

The 20-kb SMRTbell library was constructed using the SMRTbell TM Template Prep Kit (version 1.0) [36]. The 350-bp small, fragmented library was constructed using the NEBNext ${ }^{\circledR}$ Ultra ${ }^{\text {TM }}$ DNA Library Prep Kit (NEB, Ipswich, MA, USA) [37]. After the library was qualified, the whole genome of $N$. aurantialba NX-20 was sequenced using the PacBio Sequel platform and Illumina NovaSeq PE150 at the Beijing Novo Gene Bioinformatics Technology Co., Ltd. (Beijing, China) [38].

\subsubsection{Genome Assembly and Assessment}

Regarding the Illumina NovaSeq PE150 platform, firstly, SOAP denovo (version 2.04), SPAdes (version 3.1.1), and ABySS (version 2.0.2) assembly software were used to assemble the preprocessed clean data, and CISA (version 1.3) software was used for integration [39-42]. Second, GapCloser (version: 1.12) software was used to optimize the preliminary assembly results and fill holes so as to obtain the final assembly results [39]. Finally, the fragments below 500 bp were filtered out, and the contaminated samples were decontaminated again, evaluated, statistically analyzed, and subsequently used for gene prediction. 
Regarding the PacBio Sequel platform, on the basis of removing the low-quality reads (less than $500 \mathrm{bp}$ ) from the raw data, the automatic error correction function of the SMRT portal software was used to further improve the accuracy of the seed sequences, and finally, the variant caller module of the SMRT link v5.0.1 software was used to correct and count the variant sites in the initial assembly results using the arrow algorithm [43]. Benchmarking Universal Single-Copy Orthologs (BUSCO) v 3.0.2 software was used to assess the completeness of the genome assembly and single-copy ortholog annotation [44]. The lineage dataset of BUSCO was fungi_odb9 (creation date: 13 February 2016; number of species: 85; number of BUSCOs: 290). In addition, the assembly of N. aurantialba was compared with that of T. fuciformis, T. mesenterica, and N. encephala.

\subsection{Genome Component Prezdiction}

Genome component predictions were divided into predictions for coding genes, repetitive sequences, and noncoding RNAs. First, gene prediction was a combination of de-novo prediction and homology prediction, Augustus version 3.3.3 was used to de-novo predict protein coding gene models, and genomic information of $N$. encephala was used to homology predict protein coding gene models [45]. Then, the scattered repeats were predicted using RepeatMasker software (version 4.0.5), and tandem repeats finder (TRF, version $4.07 \mathrm{~b}$ ) was used to search for tandem repeats in the DNA sequences [46,47]. Finally, based on the combination of the RNA library, tRNAscan-SE software (version 1.3.1), rRNAmmer software (version 1.2), and Rfam database (version 9.1) were used to predict the structure of tRNA, rRNA, and sRNA [48-50].

\subsection{Genome Annotation}

Genomic functional annotation mainly involved BLAST alignment of the predicted genes from $N$. aurantialba against various functional databases, namely Gene Ontology, KEGG, KOG, Non-Redundant Protein Database (NR) databases, Transporter Classification Database (TCDB), Carbohydrate-Active enzymes (CAZymes), P450, and Swiss-Prot. The E-value was less than $1 \times 10^{-5}$, and the minimal alignment length percentage was larger than $40 \%$.

SignalP (version 4.1) and antiSMASH (version 6.0) software were used to predict the secretory proteins and secondary metabolic gene clusters in the N. aurantialba genome, respectively [51,52].

\subsection{Comparative Genomics Analysis}

\subsubsection{Core-Pan Genome, Phylogenetic, and Gene Family Analysis}

Core-pan genome were analyzed by the Cluster Database at High Identity with Tolerance (CD-HIT) rapid clustering of similar proteins software with a threshold of $50 \%$ pairwise identity and 0.7 length difference cutoff in amino acid [53]. TreeBeST or PhyML was adopted to construct the developmental evolutionary tree based on Muscle, and the bootstrap was set to 1000 with homologous genes [54].

Using several softwares, the gene family of $N$. aurantialba and nine other fungi was constructed: First, Blast (Version 2.2.26) was used to pairwise align all genes, after which Solar (Version 0.9.6) was used to remove redundancy, and Hcluster_sg (version 0.5.0) was used to perform gene family clustering based on the alignment results [55].

\subsubsection{Genomic Synteny}

MUMmer and LASTZ tools were used for genomic alignment, followed by genomic commonality analysis based on the alignment results [56,57].

\subsection{Other Basidiomycete Genome Sources}

The whole genome sequences of other Basidiomycetes used in the present study were downloaded from the NCBI (National Center for Biotechnology Information, https:/ / www.ncbi.nlm.nih.gov/genome, accessed on: 2 September 2021) Whole Genome Shotgun 
(WGS) database, and the U.S. Department of Energy Joint Genome Institute website (http: / / genome.jgi.doe.gov /, accessed on: 2 September 2021) (Table S1).

\section{Results and Discussion}

\subsection{Sequencing and Assembly Data}

The final genome was composed of 15 contigs after genome assembly, correction, and optimization. The total length of all assembled contigs was 20,998,359 bp with a GC content of $56.42 \%$, encoding 5860 genes with an N50 value of 1,814,705 bp. The maximum contig length among the assembled sequences was $2,546,384 \mathrm{bp}$, and the details of data generation are listed in Table 1.

Table 1. T Statistics of N. aurantialba NX-20 genome assembly and gene prediction.

\begin{tabular}{cc}
\hline Feature & Value \\
\hline Genome assembly & 15 \\
Contigs number & $2,546,384$ \\
Max length (bp) & $1,814,705$ \\
N50 length (bp) & $20,998,359$ \\
Total length (bp) & 56.42 \\
GC (\%) & 5860 \\
Gene prediction & $8,989,977$ \\
Gene number & 1534 \\
Gene total length (bp) & 42.81 \\
Gene average length (bp) & \\
Gene length/Genome (\%) &
\end{tabular}

\subsection{Genomic Features}

To date, four genomes (Tremella fuciformis tr26, Tremella mesenterica DSM 1558, Tremella mesenterica ATCC 28783, and Naematelia encephala 68-887.2) belonging to the Tremellales, an edible mushroom, are available in the NCBI WGS database. We found that N. aurantialba has a guanosine-cytosine (GC)\% similar to that of $T$. fuciformis tr26 but has a difference in length. N. aurantialba has a genomic length similar to that of N. encephala, but the GC\% is significantly different. It is striking that $N$. aurantialba differs from T. mesenterica in terms of both genome length and GC\%. In short, $N$. aurantialba has diverged somewhat from several other genomic information, which is perhaps because the whole-genome sequencing values of other genomes were obtained with only second generation sequencing technology, thereby leading to less complete genomic data, whereas our results were more precise in the way that third-generation sequencing generation sequencing combined with secondgeneration sequencing was used [58]. The details of the assembly summary statistics are presented in Table 2.

As shown in Table 2, the completeness of the genome was $93.1 \%$, and the fragmentation rate was $2.4 \%$, indicating that the completeness of the genome assembly and annotation indicated that the annotation set was complete.

\subsection{Repeat Sequence}

The repeat sequence data of $N$. aurantialba NX-20 are shown in Table 3 and were subdivided into interspersed repeats (IR) and tandem repeats (TR), in which long IRs and TR units have transposition activity and species composition specificity, respectively.

The total length of repetitive sequences was $774,977 \mathrm{bp}$, which accounted for $3.6902 \%$ of the genome length. A total of $1549 \mathrm{IR}, 191,748 \mathrm{bp}$ in length, accounted for $0.9132 \%$ of the genome length. The short interspersed nuclear elements (SINEs) and long interspersed nuclear elements (LINEs) accounted for $0.0049 \%$ and $0.1883 \%$ of the assembled genome, respectively, in the IR. TR represented $2.7775 \%$ of the assembled genomes. The Microsatellite DNA and Minisatellite DNA accounted for $0.4353 \%$ and $2.1576 \%$ of the assembled genome, respectively, in the TR. In comparison to the other three fungi's repeated sequence 
predictions (Table S2), N. aurantialba had more genes in the LINE in IR as well as Minisatellite DNA and Microsatellite DNA in TR. Microsatellite DNA can be found in both the protein-coding and noncoding sections of genes, and it plays a role in gene control, phenotypic diversity, and evolution [59]. Because it is highly polymorphic, inherited in a codominant form, and widely scattered throughout the genome, it is regarded suitable for constructing PCR-based markers in genetic investigations [60]. As a result, the findings can serve as a theoretical foundation for the development of microsatellite markers in N. aurantialba.

Table 2. Assembly summary statistics compared to other mushrooms of Tremellales.

\begin{tabular}{|c|c|c|c|c|c|c|c|c|}
\hline Species & $\begin{array}{c}\text { NCBI } \\
\text { BioProject }\end{array}$ & $\begin{array}{c}\text { Total } \\
\text { Length } \\
\text { (Mb) }\end{array}$ & GC\% & Contigs & $\begin{array}{c}\text { N50 } \\
\text { Length } \\
\text { (bp) }\end{array}$ & Completeb ${ }^{a}$ & Fragmented & Missing \\
\hline $\begin{array}{l}\text { T. fuciformis } \\
\text { Tr26 }\end{array}$ & PRJNA281519 & 23.6356 & 57.0 & 3502 & 18,448 & $92.4 \%$ & $1.4 \%$ & $6.2 \%$ \\
\hline $\begin{array}{l}\text { T. mesenterica } \\
\text { DSM } 1558\end{array}$ & PRJNA225529 & 28.6399 & 46.8 & 484 & 123,767 & $92.0 \%$ & $1.4 \%$ & $6.6 \%$ \\
\hline $\begin{array}{l}\text { T. mesenterica } \\
\text { ATCC } 28783\end{array}$ & PRJNA207298 & 27.1109 & 41.3 & 1019 & 73,463 & $90.6 \%$ & $2.4 \%$ & $7.0 \%$ \\
\hline $\begin{array}{c}\text { N. encephala } \\
68-887.2\end{array}$ & PRJNA330699 & 19.7863 & 49.3 & 151 & 209,500 & $85.5 \%$ & $3.4 \%$ & $11.1 \%$ \\
\hline $\begin{array}{l}\text { N. aurantialba } \\
\text { NX-20 }\end{array}$ & PRJNA772294 & 20.9984 & 56.4 & 15 & $1,825,336$ & $93.1 \%$ & $2.4 \%$ & $4.5 \%$ \\
\hline
\end{tabular}

Note: ${ }^{a}$ number of BUSCO proteins (percent of total BUSCOs).

Table 3. Statistical results of repeat sequences in the N. aurantialba NX-20 genome.

\begin{tabular}{|c|c|c|c|c|c|}
\hline Repeat Type & Type & $\begin{array}{l}\text { Number of } \\
\text { Elements }\end{array}$ & $\begin{array}{c}\text { Length Occupied } \\
\text { (bp) }\end{array}$ & Repeat Size (bp) & $\begin{array}{c}\text { Percentage of } \\
\text { Genome (\%) }\end{array}$ \\
\hline \multirow{6}{*}{ Interspersed repeat } & SINE & 9 & 1030 & - & 0.0049 \\
\hline & LINEs & 395 & 39,539 & - & 0.1883 \\
\hline & LTR elements & 643 & 115,566 & - & 0.5504 \\
\hline & DNA elements & 418 & 39,329 & - & 0.1873 \\
\hline & $\mathrm{RC}$ & 68 & 8542 & - & 0.0407 \\
\hline & Unknown & 16 & 1593 & - & 0.0076 \\
\hline \multirow{3}{*}{ Tandem repeat } & $\mathrm{TR}$ & 12,449 & 583,229 & $1 \sim 982$ & 2.7775 \\
\hline & Microsatellite DNA & 1448 & 91,405 & $2 \sim 6$ & 0.4353 \\
\hline & Minisatellite DNA & 9096 & 453,057 & $10 \sim 60$ & 2.1576 \\
\hline
\end{tabular}

Note: -, not detected.

\subsection{Noncoding RNA}

Noncoding RNAs (ncRNAs), a class of RNA molecules that performs a variety of biological functions and does not carry information into proteins, directly exerts its effects on life activities at the RNA level. The results of noncoding RNAs in the N. aurantialba genome are shown in Table 4 . With regard to RNA, 44 tRNAs, 11 rRNAs, and seven snRNAs were predicted. Of the tRNAs, one may be a pseudogene, and the 96 anticodon tRNAs correspond to 19 common amino acid codons. Among the rRNAs, there are 9 5s_rRNAs, 118s_rRNAs, and one 28s_rRNA. In addition, there are no miRNAs in this genome assembly because there is currently no basidiomycetes miRNA database [61]. Table S2 shows that the ncRNAs-related genes of the four edible mushrooms have poor differential conservation, which might be due to the fact that majority of the ncRNAs found in fungi of the genus mushroom have no homologs in other fungal groupings [61]. There were no snRNA encoding genes in the other three edible Tremellales fungus, but $N$. aurantialba had seven snRNA-related genes. The reason of this phenomena has to be investigated further. 
Table 4. Statistical results of noncoding RNAs in the N. aurantialba NX-20 genome.

\begin{tabular}{ccccc}
\hline Type & Number of Elements & Total Length (bp) & Average Length (bp) & Percentage in Genome (\%) \\
\hline tRNA & 44 & 3925 & 89 & 0.01869 \\
5s_rRNA & 9 & 1034 & 115 & 0.00599 \\
5.8s_rRNA & 0 & 0 & 0 & 0 \\
18s_rRNA & 1 & 1802 & 1802 & 0.02294 \\
28s_rRNA & 1 & 3492 & 3492 & 0.05030 \\
sRNA & 0 & 0 & 0 & 0 \\
snRNA & 7 & 677 & 96 & 0.00322 \\
miRNA & 0 & 0 & 0 & 0 \\
\hline
\end{tabular}

\subsection{Gene Function Annotation}

To predict the protein sequences, a similarity analysis of 5860 non-redundant genes in multiple public databases (GO, KEGG, KOG, NR, TCDB, Pfam, CAZy, P450, Swiss-Prot, SignalP, TMHMM, PHI, and DFVF) identified 5488 genes that were annotated, which accounted for $93.65 \%$ of the assembled genome. The annotation results are shown in Table S3 and Figure S1.

\subsubsection{KOG Annotations}

The KOG database is a database of orthologs for eukaryotes belonging to the COG database [62]. A statistical map of the number of annotated genes in the KOG database is shown in Figure S2. A total of 1495 genes were assigned to 24 categories of KOG, of which the top four were "Posttranslational modification, protein turnover, chaperones" (184, 12.31\%), "Translation, ribosomal structure, and biogenesis" (182, 12.17\%), "General function prediction only" (157, 10.50\%), and "Energy production and conversion" $(122,8.16 \%)$. N. aurantialba has more genes in "Lipid transport and metabolism", "Translation, ribosomal structure and biogenesis", and "Cytoskeleton" compared to the KOG annotations of the other three edible fungi (Figure S3 and Table S4). To some extent, fatty acid types can be used to distinguish Tremellales fungi types; however, strains of the same species have similar long-chain fatty acid compositions, which is due to differences in fatty acid synthetic capacity among fungi, with the number of genes being one of the most important factors affecting fatty acid synthetic capacity [63,64]. As a result, our findings suggest that $N$. aurantialba has a greater capability for fatty acid production than the other three fungi.

\subsubsection{GO Annotations}

According to the GO database, 3858 genes were assigned to three major categories: biological processes ( 24 branches), cellular components (11 branches), and molecular functions (11 branches). These were mainly distributed in four functional entries, "cellular process", "metabolic process", "binding", and "catalytic activity", of which the number of annotated genes was 2153, 1990, 1940, and 1774, respectively (Figure S4). N. aurantialba had more genes in common subcategories of "developmental process", "immune system process", "negative regulation of biological process", "reproduction", "rhythmic process", and "reproductive process" within the biological process categories and "structural molecule activity" within the molecular function categories when compared to the GO annotations of the other three fungi (Table S4). However, the number of GO functions associated with "metabolic process" was lower than in the other three fungi. The cause of this phenomena is still being investigated.

\subsubsection{KEGG Annotations}

To further systematically analyze the metabolic pathways of gene products in cells and the functions of these gene products, the KEGG database was used to annotate the gene functions of N. aurantialba. A statistical map of the number of annotated genes in the KEGG database is shown in Figure S5. Four thousand six hundred and four genes were assigned to 
six major categories in KEGG: cellular processes (five branches, 418, 9.08\%), environmental information processing (three branches, 208, 4.52\%), genetic information (four branches, $657,14.27 \%$ ), human diseases (11 branches, 615, 13.36\%), large metabolism (12 branches, $1670,36.27 \%$ ), and organismal systems (10 branches, 466, 10.12\%). N. aurantialba possesses more genes in carbohydrate metabolism than the other three fungi (Table S4), including "ascorbate and aldehyde metabolism", "citrate cycle (TCA cycle)", "inositol phosphate metabolism", and "propanoate metabolism". The findings also suggested that N. aurantialba had a high capacity for polysaccharide production.

\subsubsection{CAZymes}

In this study, the CAZy database was used to map the genome of $N$. aurantialba to study the distribution of CAZymes. A total of 207 genes were annotated as CAZymes family in this study, including 99 glycoside hydrolases (GHs), 70 glycosyl transferases (GTs), three polysaccharide lyases (PLs), 14 carbohydrate esterases (CEs), 12 carbohydrate-binding modules (CBMs), and nine auxiliary activities (AAs) (Figure 2 and Table S5).
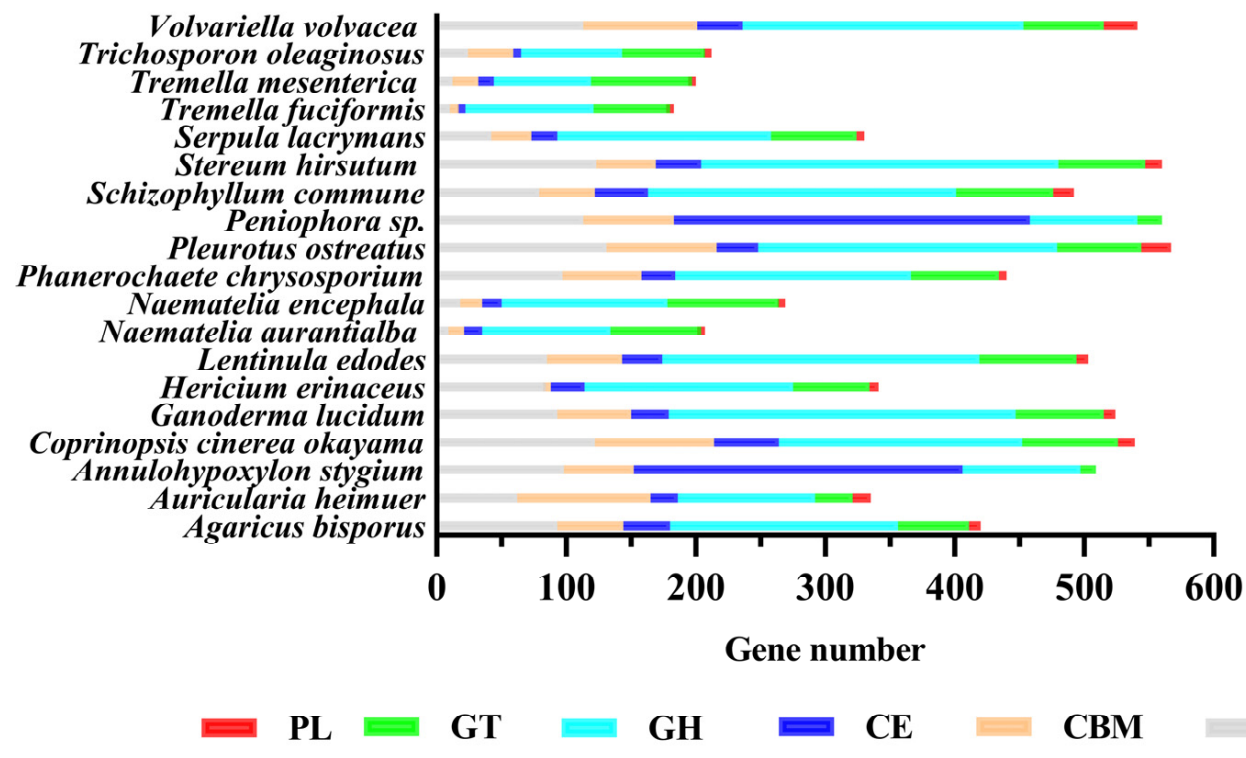

Figure 2. The number of CAZymes genes in N. aurantialba and the other 18 fungi.

In nature, the fruiting body of N. aurantialba usually grows on dead wood as a type of wood rot fungus, so it has a strong ability for lignin fiber degradation [41]. The CAZyme spectra were compared between $N$. aurantialba and 18 other Basidiomycete species. Although the number of CAZymes genes annotated by N. aurantialba was close to that of the other four fungi of the Tremellales, compared with the other 14 species of white rot fungi, the contents of AAs, GHs, CBM, and PL in N. aurantialba were much lower than their average values (Figure 2 and Table S5). This may be because N. aurantialba is a parasitic fungus with Stereum hirsutum as its host. S. hirsutum is rich in CAZymes (560 genes), and with its help, N. aurantialba is able to utilize plant cell wall polysaccharides, such as cellulose and hemicellulose. This phenomenon is very common in fungi of the Tremellales, which live parasitic lives and can utilize plant polysaccharides for growth only with the help of host fungi [65], for example, T. fuciformis (CAZymes,183 genes)-parasitized Annulohypoxylon stygium (CAZymes, 541 genes) and T. mesenterica (CAZymes, 200 genes)-parasitized Peniophora sp. (CAZymes, 593 genes). In brief, we speculated that a limited number of CAZymes could protect the host cell wall from massive destruction by parasitic fungi. The CAZyme gene annotation of $N$. aurantialba confirmed the suitability of the enzyme repertoire of this class of fungal species for parasitism and revealed strategies for host interactions with parasitic organisms (Table S5) [65]. 
In terms of quantity, the number of CAZyme genes associated with cellulases, hemicellulases, and pectinases in the $N$. aurantialba genome were 33,55 , and 17 , respectively. However, the number of genes contained by its host counterpart S. hirsutum was 132, 144, and 81 .

Compared with the abundant plant cell wall polysaccharide-degrading enzymes of S. hirsutum, N. aurantialba has almost no oxidoreductase (AA3, AA8, and AA9), cellulosedegrading enzymes (GH6, GH7, GH12, and GH44), hemicellulose-degrading enzymes (GH10, GH11, GH12, GH27, GH35, GH74, GH93, and GH95), and pectinase (GH93, PL1, PL3, and PL4). It was shown that N. aurantialba has a low number of genes identified in the genome to degrade plant cell wall polysaccharides (cellulose, hemicellulose, and pectin), whereas $S$. hirsutum has a strong ability to disintegrate. Hence, we speculated that $S$. hirsutum hydrolyzed plant cell polysaccharides into cellobiose or glucose for the development and growth of N. aurantialba during cultivation [66].

The CAZyme annotation can provide a reference not only for the analysis of polysaccharidedegrading enzyme lines but also for the analysis of polysaccharide synthetic capacity. A total of 35 genes related to the synthesis of fungal cell walls (chitin and glucan) were identified (Table S5).

\subsubsection{The Cytochromes P450 (CYPs) Family}

The cytochrome P450s (CYP450) family is a superfamily of ferrous heme thiolate proteins that are involved in physiological processes, including detoxification, xenobiotic degradation, and biosynthesis of secondary metabolites [67]. The KEGG analysis showed that $N$. aurantialba has four and four genes in "metabolism of xenobiotics by cytochrome P450" and "drug metabolism-cytochrome P450", respectively (Table S6). For further analysis, the CYP family of $N$. aurantialba was predicted using the databases (Table S6). The results showed that $N$. aurantialba contains 26 genes, with only four class CYPs, which is much lower than that of wood rot fungi, such as $S$. hirsutum (536 genes). Interestingly, Akapo et al. found that T. mesenterica (eight genes) and N. encephala (10 genes) of the Tremellales had lower numbers of CYPs [65].

This phenomenon was probably attributed to the parasitic lifestyle of fungi in the Tremellales, whose ecological niches are rich in simple-source organic nutrients, losing a considerable amount during long-term adaptation to the host-derived simple-carbonsource CYPs, thereby compressing genome size [65,68]. Intriguingly, the same phenomenon has been observed in fungal species belonging to the subphylum Saccharomycotina, where the niche is highly enriched in simple organic nutrients [69].

\subsection{Secondary Metabolites}

In the fields of modern food nutrition and pharmacology, mushrooms have attracted much interest because of their abundant secondary metabolites, which have been shown to possess various bioactive pharmacological properties, such as immunomodulatory, antiinflammatory, anti-aging, antioxidant, and antitumor [70]. A total of 215 classes of enzymes involved in "biosynthesis of secondary metabolites" (KO 01110) were predicted, as shown in Table S7.

As shown in Table S8, five gene clusters (45 genes) potentially involved in secondary metabolite biosynthesis were predicted. The predicted gene cluster included one betalactone, two NRPS-like, and two terpenes. No PKS synthesis genes were found in $N$. aurantialba, which was consistent with most Basidiomycetes. Saponin was extracted from $N$. aurantialba using a hot water extraction technique, which had a better hypolipidemic impact [71]. The phenolic and flavonoid of N. aurantialba was extracted using an organic solvent extraction technique, which revealed strong antioxidant activity $[10,72]$. Therefore, this finding suggests that $N$. aurantialba has the potential to synthesize biologically active secondary metabolites. 
In fungi, terpenes are a class of identified secondary metabolites with potent biological activities, which are usually derived from dimethylallyl diphosphate (DMAPP) and isopentenyl diphosphate (IPP), produced by acetyl coenzyme A (acetyl-CoA) via the mevalonate pathway. In this study, a total of 13 classes of enzymes involved in "terpenoid backbone biosynthesis" were identified, which generated DMAPP and IPP from acetyl CoA via the mevalonate pathway.

Like most Basidiomycetes, $N$. aurantialba had few genes of the 1-deoxy-D-xylulose 5-phosphate/2-C-methyl-D-erythritol 4-phosphate (MEP/DOXP) pathway but was enriched with genes of the DMAPP/IPP pathway (Table S8 and Figure S6) [73]. Moreover, there were a total of six classes of enzymes in the "ubiquinone and other terpenoid quinone biosynthesis" pathways, indicating that N. aurantialba may has the ability to synthesize ubiquinone [74] (Table S8).

Based on the KEGG annotation results, 12 enzymes were identified to be involved in steroid biosynthesis (Table S8). In particular, we identified a single-copy gene encoding lanosterol synthase (LSS) (Gene ID: A3811; EC No.: 1.14.14.17), which synthesizes lanosterol as a squalene or oxidosqualene cyclase family enzyme, a common triterpenoid and cyclic intermediate of steroids [75]. Synthesis of LSS was found in other Basidiomycetes [17,76,77].

For the NRPS-like, two gene clusters (22 genes) related to NRPS-like synthesis were found in the genome. Non-ribosomal peptide synthetase-like has a wide range of biological activities and pharmacological properties, including antibiotics, cytotoxins, immunosuppressants, and siderophores [78]. The NRPS genes predicted in the genome are listed in Table S8.

In addition, gene clusters related to the synthesis of betalactone were also found in the genome, and the numbers were one. It has been well known that betalactone is an antiviral heterocyclic compound [79].

The analysis was not sufficiently extensive, notwithstanding our predictions and hypotheses about the possible secondary metabolites contained in N. aurantialba. Kuhnert et al. identified and analyzed biosynthetic gene clusters of hypoxylaceae species based on blastp using Geneious software (v. 9.1.8) [80]. We can use this method to compare the secondary metabolite synthetic gene cluster of $N$. aurantialba to that of other basidiomycetes, create a secondary metabolite-based phylogenetic tree, and draw a schematic structure to gain insight into the mechanism of chemical interaction between basidiomycetes, secondary metabolites, and their environment in future work.

\subsection{Synthesis of Polysaccharides}

Polysaccharides are the main active substances found in N. aurantialba, which are generally divided into exopolysaccharides (EPS), cell wall polysaccharides (CWPS), and other polysaccharides (OPS). Studies have found that N. aurantialba polysaccharides exert their biological activities through apoptosis, mitogen-activated protein kinase (MAPK), and nuclear factor kappa B (NF-kB) signaling pathways [5].

\subsubsection{EPS}

N. aurantialba was shown to have the ability to produce high-yielding EPS in a previous study, but the mechanism of synthesis was unclear [35].

The synthesis of exopolysaccharide (EPS) by Basidiomycetes is generally divided into three steps: the synthesis of nucleotide-activated sugars, the attachment of sugar chains, and the extracellular export of polysaccharides [81]. Based on the KEGG annotation, a possible synthetic mechanism for EPS synthesis by $N$. aurantialba is discussed from these three aspects.

\section{Synthesis of Nucleotide-Activated Sugars}

The metabolic pathways of synthetic sugar nucleotides contained in the metabolism of N. aurantialba are shown in Figures S7 and S8, Table S9, and a total of 13 enzymes encoded by 15 key genes are involved in nucleotide-activated sugar synthesis. Most of these genes 
have been identified in medicinal food fungi (G. lucidum, Cordyceps, and H. erinaceus) that have been shown to affect nucleoside sugar synthesis. Furthermore, genes related to the synthesis of guanosine diphosphate (GDP)-mannose, UDP-xylose, and UDP-glucuronic acid were identified, indicating that the monosaccharide components of EPS should include mannose, xylose, and glucuronic acid. This result was consistent with previous experiments in which the monosaccharide fractions were measured [35].

\section{Linking and Modification of Sugar Chains}

In addition to the synthesis of EPS, nucleoside sugars can also synthesize other glycosylated substances, such as glycoproteins, glycolipids, and saponins. Therefore, glycosyltransferases and glycoside hydrolases are important for the synthesis of polysaccharides [51]. Glycosyl transferases are mainly responsible for the sugar chains. Linked to determine the type of polysaccharide, GHs are responsible for the role of transglycosides in polysaccharide modification [81].

\section{Extracellular Export of Polysaccharides}

There have not been complete research data on the transmembrane transport of EPS in fungi, but according to the research conducted in bacteria, the mechanism of EPS assembly and export may be relatively conservative, which usually follows Wzy-dependent or adenosine triphosphate (ATP)-binding cassette (ABC)-dependent pathways [81]. The genes that may be involved in polysaccharide transport are listed in Table S10 [81].

\subsubsection{CWPS}

The cell walls of fungi are usually chitin and glucan. Chen et al. found that the component of cell wall polysaccharide of T. fuciformis was achitin-glucan complex [82]. As shown in Table S9, we predicted 21 genes (dextran 11 and chitin 10) that may be related to cell wall synthesis in the KEGG database.

\subsubsection{OPS}

We also found 260 genes associated with other polysaccharide syntheses (N-glycan, mannose type O-glycan, and others) (Table S9).

\subsection{Biosynthesis of Bioactive Proteins, Vitamins B, Amino Acids, and Unsaturated Fatty Acids}

Bioactive proteins, vitamin B, amino acids, and unsaturated fatty acids play an important role in human health, and mushrooms are also an important source of these active substances [83].

As shown in Table S11, 20 genes related to bioactive proteins (two laccases, 14 ribonucleases, and four lectins), 89 genes related to vitamin, and seven genes related to unsaturated fatty acids in N. aurantialba were annotated.

Amino acid is one of the main reasons why mushrooms have a pleasant taste [76]. Genes involved in mushroom amino acid metabolism were predicted in N. aurantialba NX-20, wherein 32 genes were involved in glycine, serine, and threonine metabolism (sweet amino acids), and 29 genes were involved in alanine, aspartate, and glutamate metabolism (umami amino acids) (Table S11).

\subsection{Comparison with Other Basidiomycete Genomes}

\subsubsection{Gene Family, Core-Pan, and Phylogenetic Analysis}

A gene family is a collection of related genes that result from the duplication of a single initial gene [84]. The statistics of gene family numbers were obtained according to the cluster of orthologous groups based on protein sequences of strains (Figure 3A). N. aurantialba has a lower number of genes (genes number, genes in families, unclustered genes, family number, and unique families) than other strains, according to gene family analysis. Moreover, the number of genes, genes in families, unclustered genes, families, and unique families in yeast-like basidiomycetes was lower than in filamentous basidiomycetes. Gene gain or 
loss events may occur in the evolution of basidiomycetes, and gene loss events are more common than gene evolution events in the evolution of yeast-like basidiomycetes [85,86]. Thus, gene family analysis indicates that $N$. aurantialba has fewer duplications and more losses, resulting in fewer genes overall than the other three yeast-like basidiomycetes.

The CD-HIT rapid clustering of similar protein software was used to analyze the core pan of N. aurantialba with several typical basidiomycetes. Previous studies on the core-pan analysis were mostly done at the genus or family level because the only strains in the same genus or even family as $N$. aurantialba that have been sequenced are N. encephala, so the eight most typical basidiomycetes were selected and core-pan analysis was performed at the class level to investigate functional differences and similarities among the strains [87-89].

We identified 55,120 pan genes (all the genes in nine fungi) in the nine analyzed strains containing 224 conserved genes (the homologous genes that were present in all samples) and 54,896 other genes (Figure 3B), wherein A. heimuer had the most species-specific genes ( $n=10,899)$, followed by S. hirsutum $(n=9828)$, G. lucidum $(n=8073)$, H. erinaceus $(n=6132)$, NX-20 $(n=2317)$, T. fuciformis $(n=4074), N$. encephala $(n=3423)$, and T. mesenterica $(n=2079$ and 2250).

The results of phylogenetic analysis are shown in Figure 3C; N. aurantialba NX-20 had the greatest taxonomically related to N. encephala, followed by T. fuciformis and then T. mesenterica.

$\mathbf{A}$

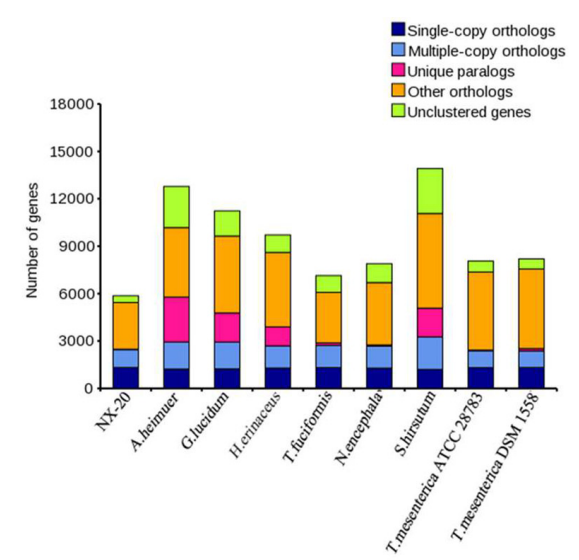

B

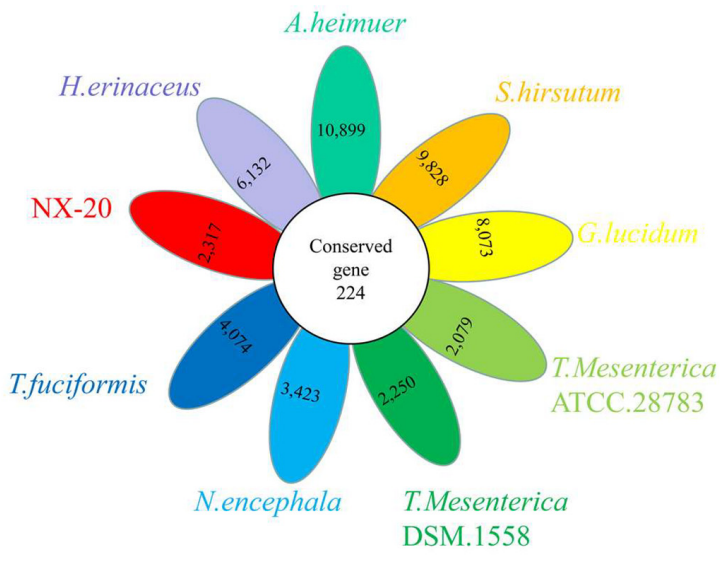

C - Auricularia.heimuer.Dai.13782

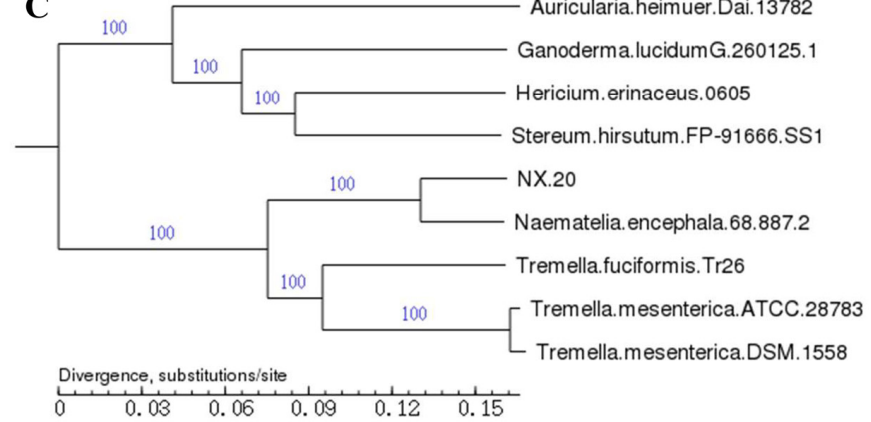

Figure 3. Comparative genomics analysis. (A) Gene family (Single-Copy Orthologs, the number of single-copy homologous genes in the species common gene families; Multiple-Copy Orthologs, the number of multiple-copy homologous genes in the species common gene families; Unique Paralogs, genes in specific gene families; Other Orthologs, other genes; Unclustered Genes, genes that have not been clustered into any families); (B) conserved and specific gene counts (each ellipse represents a strain, and the numbers in the ellipses are specific genes. In addition, the central white circle represents conserved genes among the nine strains); (C) maximum likelihood phylogenetic tree.

\subsubsection{Genomic Synteny}

Figure 4 shows the collinearity of genes in the whole genome sequences of N. aurantialba NX-20 and three mushrooms belonging to the order Tremellales. 
We found that NX-20 had the highest collinearity with N. encephala 68-887.2 (15.08\%), followed by T. mesenterica DSM 1558 (11.47\%) and T. fuciformis tr26 (6.95\%). This result further showed the closer proximity of NX-20 to N. encephala 68-887.2, and grouping NX-20 into the genus Naematelia rather than Tremella might be a more appropriate choice.

A Forvard_chain
Reversechain

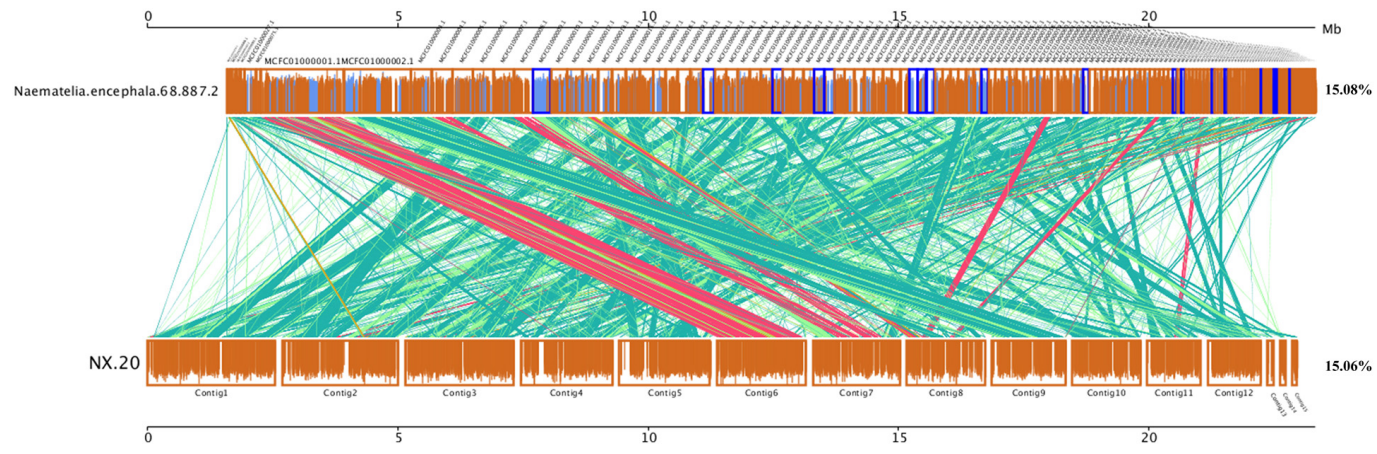

B

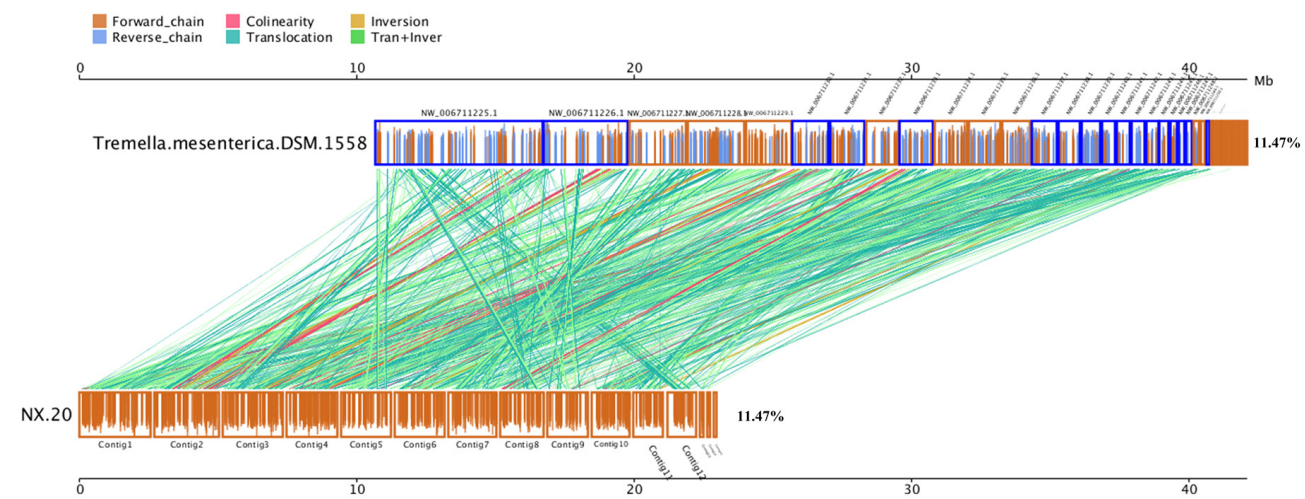

C

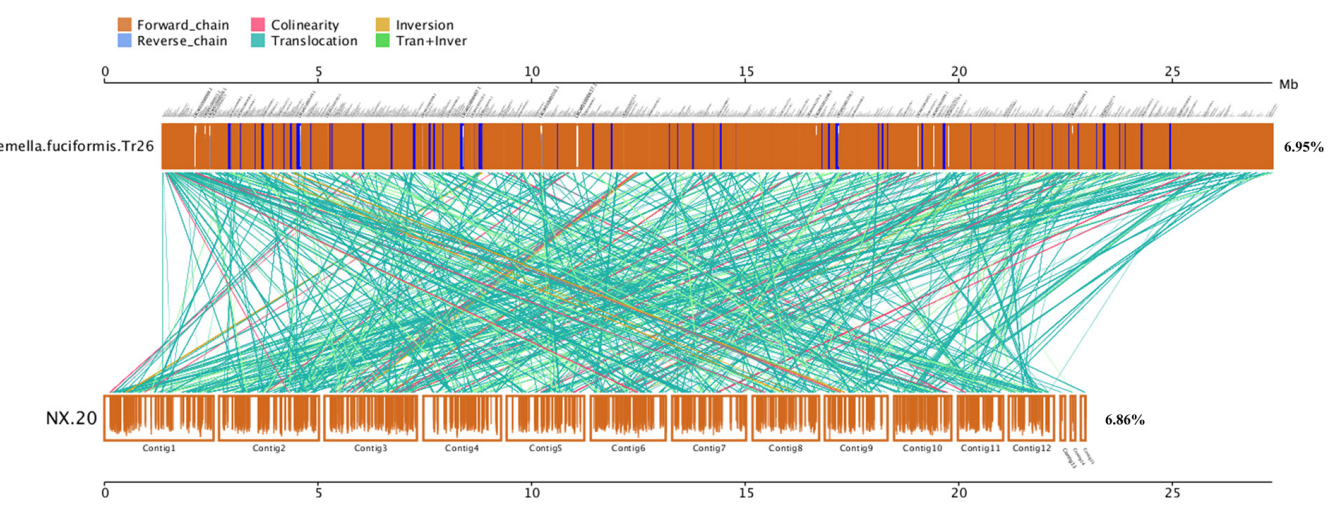

Figure 4. Synteny of N. aurantialba NX-20 with N. encephala 68-887.2 (A), T. mesenterica DSM 1558 (B), and Tremella fuciformis $\operatorname{Tr} 26$ (C). The upper axis indicates the genome measured, and the lower axis indicates the reference sequence genome. The forward and reverse strands are represented by yellow boxes and blue boxes, respectively. The height of the filled color in the box indicates the similarity of the alignment, and full filling indicates $100 \%$ similarity. The color of the linked graph between the upper and lower axes indicates the alignment type: Collinear, syntenic alignment; Translocation, translocation alignment; Inversion, inverted alignment; Tran + inver, alignment of translocations and inversions. 


\section{Conclusions}

Genome sequencing and functional annotation provide valuable information for determining the potential function and gene expression mechanism, which can be used to provide a theoretical basis for N. aurantialba breeding, high-yield cultivation, and the construction of molecular biology platforms. This study showed that N. aurantialba NX-20 has the potential to be used to synthesize a variety of secondary metabolites, especially highly enriched polysaccharides and terpenoid biosynthesis genes, providing important insights into the biological properties of the medicinal food fungus N. aurantialba through whole-genome sequencing, including its gene regulatory network, growth characteristics, and biosynthetic pathways of active compounds, among others. In addition, this study is expected to provide fundamental information for developing mushroom genomes and genetic resources to elucidate the molecular mechanisms underlying the synthesis of multiple secondary metabolites in pharmaceutical edible mushrooms. To the best of our knowledge, this genome-wide assembly and annotation data represent the first genomescale assembly of this species.

Although the relevant information was incomplete, the analysis of the N. aurantialba genome in this study fills the gap in genomic information on N. aurantialba and will lay a theoretical foundation for future research on the biosynthesis of active compounds, promoting the application of $N$. aurantialba in the field of drug research and functional food development.

Supplementary Materials: The following are available online at https:/ /www.mdpi.com/article/ 10.3390/jof8010006/s1, Figure S1: Summarizes of the annotations of N. aurantialba; Figure S2: The KOG function classification of proteins in N. aurantialba; Figure S3: Comparative genomics analysis of KOG annotations; Figure S4: The GO function annotation of N. aurantialba; Figure S5: The KEGG function annotation of N. aurantialba; Figure S6: Terpenoid biosynthesis pathway of N. aurantialba; Figure S7: Amino sugar and nucleotide sugar metabolic pathway in N. aurantialba; Figure S8: Putative nucleoside sugar biosynthetic pathway of N. aurantialba; Table S1: Basidiomycetes and the origin of their genomes used in the study; Table S2: Comparative genomics analysis of Repeat sequence and Noncoding RNA; Table S3: Summarizes of the annotations of Naematelia aurantialba; Table S4: Comparative genomics analysis of KOG, GO, and KEGG annotations; Table S5: Distribution of CAZyme in Naematelia aurantialba and the other 18 basidiomycetes; Table S6: P450 genes and subfamilies in Naematelia aurantialba; Table S7: The putative enzyme-coding genes involved in biosynthesis of secondary metabolites; Table S8: The putative genes involved in secondary metabolism of Naematelia aurantialba; Table S9: The putative genes involved in polysaccharides biosynthesis of Naematelia aurantialba; Table S10: Putative genes involved in ABC-dependent pathways; Table S11: The putative genes involved in biosynthesis of bioactive proteins, vitamins $B$, amino acids, and unsaturated fatty acids of Naematelia aurantialba.

Author Contributions: Conceptualization, P.L. and H.X.; methodology, P.L.; software, R.W. and Y.Q.; validation, D.S.; formal analysis, T.S. and S.W.; investigation, H.J.; resources, P.L.; data curation, T.S.; writing—original draft preparation, T.S. and Y.Z.; writing—review and editing, T.S. and K.Y.; visualization, S.L.; supervision, P.L.; project administration, P.L. and H.X. All authors have read and agreed to the published version of the manuscript.

Funding: The research was funded by National Key Research and Development Program of China (2021YFC2101700), the National Natural Science Foundation of China (31800101), China Postdoctoral Science Foundation (2020M671468), State Key Laboratory Open Foundation (ZK201905), and National Students' platform for innovation and entrepreneurship training program (202110291042Z).

Institutional Review Board Statement: Not applicable.

Informed Consent Statement: Not applicable.

Data Availability Statement: Genome sequencing of N. aurantialba-20 generated for this study have been submitted to the NCBI (https: / / www.ncbi.nlm.nih.gov, accessed on: 1 November 2021). BioProject: PRJNA772294 and BioSample: SAMN22141859. 


\begin{abstract}
Acknowledgments: We thank the U.S. Department of Energy Joint Genome Institute (http:/ / www. jgi.doe.gov/, accessed on: 2 September 2021) in collaboration with the user community and the National Center for Biotechnology Information (https: / www.ncbi.nlm.nih.gov/genome, accessed on: 2 September 2021) for providing most of the sequencing data for fungi used in this study.
\end{abstract}

Conflicts of Interest: The authors declare no conflict of interest.

\title{
References
}

1. Zhao, S.; Gao, Q.; Rong, C.; Wang, S.; Zhao, Z.; Liu, Y.; Xu, J. Immunomodulatory effects of edible and medicinal mushrooms and their bioactive immunoregulatory products. J. Fungi 2020, 6, 269. [CrossRef]

2. Lu, H.; Lou, H.; Hu, J.; Liu, Z.; Chen, Q. Macrofungi: A review of cultivation strategies, bioactivity, and application of mushrooms. Compr. Rev. Food Sci. F 2020, 19, 2333-2356. [CrossRef]

3. Niazi, A.R.; Ghafoor, A. Different ways to exploit mushrooms: A review. All Life 2021, 14, 450-460. [CrossRef]

4. Du, X.; Zhang, Y.; Mu, H.; Lv, Z.; Yang, Y.; Zhang, J. Structural elucidation and antioxidant activity of a novel polysaccharide (TAPB1) from Tremella aurantialba. Food Hydrocoll. 2015, 43, 459-464. [CrossRef]

5. Yuan, Q.; Zhang, X.; Ma, M.; Long, T.; Xiao, C.; Zhang, J.; Liu, J.; Zhao, L. Immunoenhancing glucuronoxylomannan from Tremella aurantialba Bandoni et Zang and its low-molecular-weight fractions by radical depolymerization: Properties, structures and effects on macrophages. Carbohydr. Polym. 2020, 238, 116184. [CrossRef] [PubMed]

6. Deng, C.; Sun, Y.; Fu, H.; Zhang, S.; Chen, J.; Xu, X. Antioxidant and immunostimulatory activities of polysaccharides extracted from Tremella aurantialba mycelia. Mol. Med. Rep. 2016, 14, 4857-4864. [CrossRef] [PubMed]

7. Zhou, S.; Tang, Q.; Zhang, Z.; Li, C.-h.; Cao, H.; Yang, Y.; Zhang, J. Nutritional composition of three domesticated culinarymedicinal mushrooms: Oudemansiella sudmusida, Lentinus squarrosulus, and Tremella aurantialba. Int. J. Med. Mushrooms 2015, 17, 43-49. [CrossRef]

8. Fan, J.; Chu, Z.; Li, L.; Zhao, T.; Yin, M.; Qin, Y. Physicochemical properties and microbial quality of tremella aurantialba packed in antimicrobial composite films. Molecules 2017, 22, 500. [CrossRef] [PubMed]

9. Du, X.; Wang, X.; Chen, Y.; Tian, S.; Lu, S. Antioxidant activity and oxidative injury rehabilitation of chemically modified polysaccharide (TAPA1) from Tremella aurantialba. Macromol. Res. 2018, 26, 479-483. [CrossRef]

10. Islam, T.; Yu, X.; Xu, B. Phenolic profiles, antioxidant capacities and metal chelating ability of edible mushrooms commonly consumed in China. LWT 2016, 72, 423-431. [CrossRef]

11. Bandoni, R.; Zang, M. On an undescribed Tremella from China. Mycologia 1990, 82, 270-273. [CrossRef]

12. Liu, D.; Pujiana, D.; Wang, Y.; Zhang, Z.; Zheng, L.; Chen, L.; Ma, A. Comparative transcriptomic analysis identified differentially expressed genes and pathways involved in the interaction between Tremella fuciformis and Annulohypoxylon stygium. Antonie Van Leeuwenhoek 2019, 112, 1675-1689. [CrossRef]

13. Li, H.-J.; Zhang, D.-H.; Yue, T.-H.; Jiang, L.-X.; Yu, X.; Zhao, P.; Li, T.; Xu, J.-W. Improved polysaccharide production in a submerged culture of Ganoderma lucidum by the heterologous expression of Vitreoscilla hemoglobin gene. J. Biotechnol. 2016, 217, 132-137. [CrossRef]

14. Wang, T.; Wang, Y.; Chen, C.; Ren, A.; Yu, H.; Zhao, M. Effect of the heme oxygenase gene on mycelial growth and polysaccharide synthesis in Ganoderma lucidum. J. Basic Microbiol. 2021, 61, 253-264. [CrossRef]

15. Zhou, J.; Bai, Y.; Dai, R.; Guo, X.; Liu, Z.-H.; Yuan, S. Improved polysaccharide production by homologous co-overexpression of phosphoglucomutase and UDP glucose pyrophosphorylase genes in the mushroom Coprinopsis cinerea. J. Agric. Food Chem. 2018, 66, 4702-4709. [CrossRef]

16. Zan, X.-Y.; Zhu, H.-A.; Jiang, L.-H.; Liang, Y.-Y.; Sun, W.-J.; Tao, T.-L.; Cui, F.-J. The role of Rho1 gene in the cell wall integrity and polysaccharides biosynthesis of the edible mushroom Grifola frondosa. Int. J. Biol. Macromol. 2020, 165, 1593-1603. [CrossRef]

17. Yuan, Y.; Wu, F.; Si, J.; Zhao, Y.-F.; Dai, Y.-C. Whole genome sequence of Auricularia heimuer (Basidiomycota, Fungi), the third most important cultivated mushroom worldwide. Genomics 2019, 111, 50-58. [CrossRef]

18. Yap, H.-Y.Y.; Muria-Gonzalez, M.J.; Kong, B.-H.; Stubbs, K.A.; Tan, C.-S.; Ng, S.-T.; Tan, N.-H.; Solomon, P.S.; Fung, S.-Y.; Chooi, Y.-H. Heterologous expression of cytotoxic sesquiterpenoids from the medicinal mushroom Lignosus rhinocerotis in yeast. Microb. Cell Factories 2017, 16, 103. [CrossRef]

19. O'Connor, E.; McGowan, J.; McCarthy, C.G.; Amini, A.; Grogan, H.; Fitzpatrick, D.A. Whole genome sequence of the commercially relevant mushroom strain Agaricus bisporus var. bisporus ARP23. G3 Genes Genomes Genet. 2019, 9, 3057-3066.

20. Gea, F.J.; Navarro, M.J.; Santos, M.; Diánez, F.; Carrasco, J. Control of Fungal Diseases in Mushroom Crops while Dealing with Fungicide Resistance: A Review. Microorganisms 2021, 9, 585. [CrossRef]

21. Gong, W.; Wang, Y.; Xie, C.; Zhou, Y.; Zhu, Z.; Peng, Y. Whole genome sequence of an edible and medicinal mushroom, Hericium erinaceus (Basidiomycota, Fungi). Genomics 2020, 112, 2393-2399. [CrossRef] [PubMed]

22. Shao, Y.; Guo, H.; Zhang, J.; Liu, H.; Wang, K.; Zuo, S.; Xu, P.; Xia, Z.; Zhou, Q.; Zhang, H. The genome of the medicinal macrofungus Sanghuang provides insights into the synthesis of diverse secondary metabolites. Front. Microbiol. 2020, 10, 3035. [CrossRef] [PubMed]

23. Jiang, J.-H.; Wu, S.-H.; Zhou, L.-W. The First Whole Genome Sequencing of Sanghuangporus sanghuang Provides Insights into Its Medicinal Application and Evolution. J. Fungi 2021, 7, 787. [CrossRef] [PubMed] 
24. Sharma, V.P.; Barh, A.; Bairwa, R.K.; Annepu, S.K.; Kumari, B.; Kamal, S. Enoki Mushroom (Flammulina velutipes (Curtis) Singer) Breeding. In Advances in Plant Breeding Strategies: Vegetable Crops; Springer: Cham, Switzerland, 2021; pp. $423-441$.

25. Chen, J.; Li, J.-M.; Tang, Y.-J.; Ma, K.; Li, B.; Zeng, X.; Liu, X.-B.; Li, Y.; Yang, Z.-L.; Xu, W.-N. Genome-wide analysis and prediction of genes involved in the biosynthesis of polysaccharides and bioactive secondary metabolites in high-temperature-tolerant wild Flammulina filiformis. BMC Genom. 2020, 21, 719. [CrossRef]

26. Luo Xingye, L.; Baxian, C.; Zhisen, L. Yunnan golden fungus (Tremella mesenterica Retz ex Fr.), a rarity in recipe. Yunnan Agric. Sci. Technol. 1987, 2, 44-46.

27. Liu, X.-Z.; Wang, Q.-M.; Göker, M.; Groenewald, M.; Kachalkin, A.; Lumbsch, H.T.; Millanes, A.; Wedin, M.; Yurkov, A.; Boekhout, T. Towards an integrated phylogenetic classification of the Tremellomycetes. Stud. Mycol. 2015, 81, 85-147. [CrossRef]

28. Morin, E.; Kohler, A.; Baker, A.R.; Foulongne-Oriol, M.; Lombard, V.; Nagye, L.G.; Ohm, R.A.; Patyshakuliyeva, A.; Brun, A.; Aerts, A.L. Genome sequence of the button mushroom Agaricus bisporus reveals mechanisms governing adaptation to a humic-rich ecological niche. Proc. Natl. Acad. Sci. USA 2012, 109, 17501-17506. [CrossRef]

29. Stajich, J.E.; Wilke, S.K.; Ahrén, D.; Au, C.H.; Birren, B.W.; Borodovsky, M.; Burns, C.; Canbäck, B.; Casselton, L.A.; Cheng, C. Insights into evolution of multicellular fungi from the assembled chromosomes of the mushroom Coprinopsis cinerea (Coprinus cinereus). Proc. Natl. Acad. Sci. USA 2010, 107, 11889-11894. [CrossRef]

30. Chen, S.; Xu, J.; Liu, C.; Zhu, Y.; Nelson, D.R.; Zhou, S.; Li, C.; Wang, L.; Guo, X.; Sun, Y. Genome sequence of the model medicinal mushroom Ganoderma lucidum. Nat. Commun. 2012, 3, 913. [CrossRef] [PubMed]

31. Shim, D.; Park, S.-G.; Kim, K.; Bae, W.; Lee, G.W.; Ha, B.-S.; Ro, H.-S.; Kim, M.; Ryoo, R.; Rhee, S.-K. Whole genome de novo sequencing and genome annotation of the world popular cultivated edible mushroom, Lentinula edodes. J. Biotechnol. 2016, 223, 24-25. [CrossRef]

32. Mondo, S.J.; Dannebaum, R.O.; Kuo, R.C.; Louie, K.B.; Bewick, A.J.; LaButti, K.; Haridas, S.; Kuo, A.; Salamov, A.; Ahrendt, S.R. Widespread adenine N6-methylation of active genes in fungi. Nat. Genet. 2017, 49, 964-968. [CrossRef]

33. Deng, Y.; Huang, X.; Ruan, B.; Xie, B.; van Peer, A.F.; Jiang, Y. Optimal codons in Tremella fuciformis end in C/G, a strong difference with known Tremella species. World J. Microbiol. Biotechnol. 2015, 31, 1691-1698. [CrossRef] [PubMed]

34. Floudas, D.; Binder, M.; Riley, R.; Barry, K.; Blanchette, R.A.; Henrissat, B.; Martínez, A.T.; Otillar, R.; Spatafora, J.W.; Yadav, J.S. The Paleozoic origin of enzymatic lignin decomposition reconstructed from 31 fungal genomes. Science 2012, 336, 1715-1719. [CrossRef] [PubMed]

35. Sun, T.; Wang, R.; Sun, D.; Li, S.; Xu, H.; Qiu, Y.; Lei, P.; Sun, L.; Xu, X.; Zhu, Y. High-efficiency production of Tremella aurantialba polysaccharide through basidiospore fermentation. Bioresour. Technol. 2020, 318, 124268. [CrossRef] [PubMed]

36. Kang, S.-H.; Lee, W.-H.; Lee, C.-M.; Sim, J.-S.; Won, S.Y.; Han, S.-R.; Kwon, S.-J.; Kim, J.S.; Kim, C.-K.; Oh, T.-J. De novo transcriptome sequence of Senna tora provides insights into anthraquinone biosynthesis. PLoS ONE 2020, 15, e0225564. [CrossRef] [PubMed]

37. Jia, N.; Wang, J.; Shi, W.; Du, L.; Sun, Y.; Zhan, W.; Jiang, J.-F.; Wang, Q.; Zhang, B.; Ji, P. Large-scale comparative analyses of tick genomes elucidate their genetic diversity and vector capacities. Cell 2020, 182, 1328-1340.e1313. [CrossRef]

38. Zhou, J.; Sun, T.; Kang, W.; Tang, D.; Feng, Q. Pathogenic and antimicrobial resistance genes in Streptococcus oralis strains revealed by comparative genome analysis. Genomics 2020, 112, 3783-3793. [CrossRef]

39. Luo, R.; Liu, B.; Xie, Y.; Li, Z.; Huang, W.; Yuan, J.; He, G.; Chen, Y.; Pan, Q.; Liu, Y. SOAPdenovo2: An empirically improved memory-efficient short-read de novo assembler. Gigascience 2012, 1, 2047-2217X-1-18. [CrossRef]

40. Bankevich, A.; Nurk, S.; Antipov, D.; Gurevich, A.A.; Dvorkin, M.; Kulikov, A.S.; Lesin, V.M.; Nikolenko, S.I.; Pham, S.; Prjibelski, A.D. SPAdes: A new genome assembly algorithm and its applications to single-cell sequencing. J. Comput. Biol. 2012, 19, 455-477. [CrossRef]

41. Jackman, S.D.; Vandervalk, B.P.; Mohamadi, H.; Chu, J.; Yeo, S.; Hammond, S.A.; Jahesh, G.; Khan, H.; Coombe, L.; Warren, R.L. ABySS 2.0: Resource-efficient assembly of large genomes using a Bloom filter. Genome Res. 2017, 27, 768-777. [CrossRef]

42. Lin, S.-H.; Liao, Y.-C. CISA: Contig integrator for sequence assembly of bacterial genomes. PLoS ONE 2013, 8, e60843. [CrossRef]

43. Berlin, K.; Koren, S.; Chin, C.-S.; Drake, J.P.; Landolin, J.M.; Phillippy, A.M. Assembling large genomes with single-molecule sequencing and locality-sensitive hashing. Nat. Biotechnol. 2015, 33, 623-630. [CrossRef] [PubMed]

44. Simão, F.A.; Waterhouse, R.M.; Ioannidis, P.; Kriventseva, E.V.; Zdobnov, E.M. BUSCO: Assessing genome assembly and annotation completeness with single-copy orthologs. Bioinformatics 2015, 31, 3210-3212. [CrossRef] [PubMed]

45. Hoff, K.J.; Stanke, M. WebAUGUSTUS-A web service for training AUGUSTUS and predicting genes in eukaryotes. Nucleic Acids Res. 2013, 41, W123-W128. [CrossRef] [PubMed]

46. Benson, G. Tandem repeats finder: A program to analyze DNA sequences. Nucleic Acids Res. 1999, 27, 573-580. [CrossRef]

47. Smit, A.F. Repeat-Masker Open-3.0. 2010. Available online: http:/ / www.repeatmasker.org (accessed on 5 August 2021).

48. Lowe, T.M.; Eddy, S.R. tRNAscan-SE: A program for improved detection of transfer RNA genes in genomic sequence. Nucleic Acids Res. 1997, 25, 955-964. [CrossRef]

49. Lagesen, K.; Hallin, P.; Rødland, E.A.; Stærfeldt, H.-H.; Rognes, T.; Ussery, D.W. RNAmmer: Consistent and rapid annotation of ribosomal RNA genes. Nucleic Acids Res. 2007, 35, 3100-3108. [CrossRef]

50. Griffiths-Jones, S.; Moxon, S.; Marshall, M.; Khanna, A.; Eddy, S.R.; Bateman, A. Rfam: Annotating non-coding RNAs in complete genomes. Nucleic Acids Res. 2005, 33, D121-D124. [CrossRef]

51. Nielsen, H. Predicting secretory proteins with SignalP. In Protein Function Prediction; Springer: Berlin, Germany, $2017 ;$ pp. 59-73. 
52. Blin, K.; Shaw, S.; Kloosterman, A.M.; Charlop-Powers, Z.; van Wezel, G.P.; Medema, M.H.; Weber, T. antiSMASH 6.0: Improving cluster detection and comparison capabilities. Nucleic Acids Res. 2021, 1, W29-W35. [CrossRef]

53. Fu, L.; Niu, B.; Zhu, Z.; Wu, S.; Li, W. CD-HIT: Accelerated for clustering the next-generation sequencing data. Bioinformatics 2012, 28, 3150-3152. [CrossRef]

54. Vilella, A.J.; Severin, J.; Ureta-Vidal, A.; Heng, L.; Durbin, R.; Birney, E. EnsemblCompara GeneTrees: Complete, duplication-aware phylogenetic trees in vertebrates. Genome Res. 2009, 19, 327-335. [CrossRef] [PubMed]

55. Altschul, S.F.; Gish, W.; Miller, W.; Myers, E.W.; Lipman, D.J. Basic local alignment search tool. J. Mol. Biol. 1990, 215, 403-410. [CrossRef]

56. Kurtz, S.; Phillippy, A.; Delcher, A.L.; Smoot, M.; Shumway, M.; Antonescu, C.; Salzberg, S.L. Versatile and open software for comparing large genomes. Genome Biol. 2004, 5, R12. [CrossRef] [PubMed]

57. Harris, R.S. Improved Pairwise Alignment of Genomic DNA; The Pennsylvania State University: State College, PA, USA, 2007.

58. Liu, L.; Li, Y.; Li, S.; Hu, N.; He, Y.; Pong, R.; Lin, D.; Lu, L.; Law, M. Comparison of next-generation sequencing systems. J. Biomed. Biotechnol. 2012, 2012, 251364. [CrossRef] [PubMed]

59. Zane, L.; Bargelloni, L.; Patarnello, T. Strategies for microsatellite isolation: A review. Mol. Ecol. 2002, 11, 1-16. [CrossRef] [PubMed]

60. Bilgen, M.; Karaca, M.; Onus, A.N.; Ince, A.G. A software program combining sequence motif searches with keywords for finding repeats containing DNA sequences. Bioinformatics 2004, 20, 3379-3386. [CrossRef] [PubMed]

61. Qu, J.; Zhao, M.; Hsiang, T.; Feng, X.; Zhang, J.; Huang, C. Identification and characterization of small noncoding RNAs in genome sequences of the edible fungus Pleurotus ostreatus. BioMed Res. Int. 2016, 2016, 2503023. [CrossRef]

62. Yin, J.; Jiang, L.; Wang, L.; Han, X.; Guo, W.; Li, C.; Zhou, Y.; Denton, M.; Zhang, P. A high-quality genome of taro (Colocasia esculenta (L.) Schott), one of the world's oldest crops. Mol. Ecol. Resour. 2021, 21, 68-77. [CrossRef]

63. Smit, E.; Kock, J.; Van Der Wsthuizen, J.; Britz, T. Taxonomic relationships of Cryptococcus and Tremella based on fatty acid composition and other phenotypic characters. Microbiology 1988, 134, 2849-2855. [CrossRef]

64. Chang, L.; Lu, H.; Chen, H.; Tang, X.; Zhao, J.; Zhang, H.; Chen, Y.Q.; Chen, W. Lipid metabolism research in oleaginous fungus Mortierella alpina: Current progress and future prospects. Biotechnol. Adv. 2021, 107794. [CrossRef]

65. Akapo, O.O.; Padayachee, T.; Chen, W.; Kappo, A.P.; Yu, J.-H.; Nelson, D.R.; Syed, K. Distribution and diversity of cytochrome P450 monooxygenases in the fungal class Tremellomycetes. Int. J. Mol. Sci. 2019, 20, 2889. [CrossRef] [PubMed]

66. Rytioja, J.; Hildén, K.; Yuzon, J.; Hatakka, A.; De Vries, R.P.; Mäkelä, M.R. Plant-polysaccharide-degrading enzymes from basidiomycetes. Microbiol. Mol. Biol. Rev. 2014, 78, 614-649. [CrossRef] [PubMed]

67. Bhattacharyya, S.; Sinha, K.; Sil, C.P. Cytochrome P450s: Mechanisms and biological implications in drug metabolism and its interaction with oxidative stress. Curr. Drug Metab. 2014, 15, 719-742. [CrossRef] [PubMed]

68. Aliyu, H.; Gorte, O.; Zhou, X.; Neumann, A.; Ochsenreither, K. In silico proteomic analysis provides insights into phylogenomics and plant biomass deconstruction potentials of the tremelalles. Front. Bioeng. Biotechnol. 2020, 8, 226. [CrossRef] [PubMed]

69. Kgosiemang, I.K.R.; Syed, K.; Mashele, S.S. Comparative genomics and evolutionary analysis of cytochrome P450 monooxygenases in fungal subphylum Saccharomycotina. J. Pure Appl. Microbiol. 2014, 8, 291-302.

70. Ogidi, C.O.; Oyetayo, V.O.; Akinyele, B.J. Wild Medicinal Mushrooms: Potential Applications in Phytomedicine and Functional Foods. In An Introduction to Mushroom; IntechOpen: Vienna, Austria, 2020; pp. 118-126.

71. Zhang, Z.; Lian, B.; Huang, D.; Cui, F. Compare activities on regulating lipid-metabolism and reducing oxidative stress of diabetic rats of Tremella aurantialba broth's extract (TBE) with its mycelia polysaccharides (TMP). J. Food Sci. 2009, 74, H15-H21. [CrossRef] [PubMed]

72. Guo, Y.-J.; Deng, G.-F.; Xu, X.-R.; Wu, S.; Li, S.; Xia, E.-Q.; Li, F.; Chen, F.; Ling, W.-H.; Li, H.-B. Antioxidant capacities, phenolic compounds and polysaccharide contents of 49 edible macro-fungi. Food Funct. 2012, 3, 1195-1205. [CrossRef]

73. Liu, D.; Gong, J.; Dai, W.; Kang, X.; Huang, Z.; Zhang, H.-M.; Liu, W.; Liu, L.; Ma, J.; Xia, Z. The genome of Ganderma lucidum provide insights into triterpense biosynthesis and wood degradation. PLoS ONE 2012, 7, e36146.

74. Liang, Y.; Lu, D.; Wang, S.; Zhao, Y.; Gao, S.; Han, R.; Yu, J.; Zheng, W.; Geng, J.; Hu, S. Genome assembly and pathway analysis of edible mushroom Agrocybe cylindracea. Genom. Proteom. Bioinform. 2020, 18, 341-351. [CrossRef]

75. Wang, W.F.; Xiao, H.; Zhong, J.J. Biosynthesis of a ganoderic acid in Saccharomyces cerevisiae by expressing a cytochrome P450 gene from Ganoderma lucidum. Biotechnol. Bioeng. 2018, 115, 1842-1854. [CrossRef]

76. Yu, F.; Song, J.; Liang, J.; Wang, S.; Lu, J. Whole genome sequencing and genome annotation of the wild edible mushroom, Russula griseocarnosa. Genomics 2020, 112, 603-614. [CrossRef] [PubMed]

77. Yap, H.-Y.Y.; Chooi, Y.-H.; Firdaus-Raih, M.; Fung, S.-Y.; Ng, S.-T.; Tan, C.-S.; Tan, N.-H. The genome of the Tiger Milk mushroom, Lignosus rhinocerotis, provides insights into the genetic basis of its medicinal properties. BMC Genom. 2014, 15, 635. [CrossRef] [PubMed]

78. Schüffler, A. Secondary metabolites of basidiomycetes. In Physiology and Genetics; Springer: Berlin/Heidelberg, Germany, 2018; pp. 231-275.

79. Fenteany, G.; Standaert, R.F.; Reichard, G.A.; Corey, E.; Schreiber, S.L. A beta-lactone related to lactacystin induces neurite outgrowth in a neuroblastoma cell line and inhibits cell cycle progression in an osteosarcoma cell line. Proc. Natl. Acad. Sci. USA 1994, 91, 3358-3362. [CrossRef] [PubMed] 
80. Kuhnert, E.; Navarro-Muñoz, J.; Becker, K.; Stadler, M.; Collemare, J.; Cox, R. Secondary metabolite biosynthetic diversity in the fungal family Hypoxylaceae and Xylaria hypoxylon. Stud. Mycol. 2021, 99, 100118. [CrossRef] [PubMed]

81. Yang, S.; Yang, X.; Zhang, H. Extracellular polysaccharide biosynthesis in Cordyceps. Crit. Rev. Microbiol. 2020, 46, 359-380. [CrossRef]

82. Rana, S.; Upadhyay, L.S.B. Microbial exopolysaccharides: Synthesis pathways, types and their commercial applications. Int. J. Biol. Macromol. 2020, 157, 577-583. [CrossRef] [PubMed]

83. Rathore, H.; Prasad, S.; Sharma, S. Mushroom nutraceuticals for improved nutrition and better human health: A review. Pharma. Nutr. 2017, 5, 35-46. [CrossRef]

84. Yu, Z.; Wang, E.; Geng, Y.; Wang, K.; Chen, D.; Huang, X.; Ouyang, P.; Zuo, Z.; Huang, C.; Fang, J. Complete genome analysis of Vibrio mimicus strain SCCF01, a highly virulent isolate from the freshwater catfish. Virulence 2020, 11, 23-31. [CrossRef]

85. Nagy, L.G.; Ohm, R.A.; Kovács, G.M.; Floudas, D.; Riley, R.; Gácser, A.; Sipiczki, M.; Davis, J.M.; Doty, S.L.; De Hoog, G.S. Latent homology and convergent regulatory evolution underlies the repeated emergence of yeasts. Nat. Commun. $2014,5,4471$. [CrossRef]

86. Nagy, L.G. Evolution: Complex multicellular life with 5500 genes. Curr. Biol. 2017, 27, R609-R612. [CrossRef]

87. Xu, P.; Wang, H.; Qin, C.; Li, Z.; Lin, C.; Liu, W.; Miao, W. Analysis of the Taxonomy and Pathogenic Factors of Pectobacterium aroidearum L6 Using Whole-Genome Sequencing and Comparative Genomics. Front. Microbiol. 2021, 12, 1770. [CrossRef] [PubMed]

88. Alcaraz, L.D.; Moreno-Hagelsieb, G.; Eguiarte, L.E.; Souza, V.; Herrera-Estrella, L.; Olmedo, G. Understanding the evolutionary relationships and major traits of Bacillus through comparative genomics. BMC Genom. 2010, 11, 332. [CrossRef] [PubMed]

89. González-Dominici, L.I.; Saati-Santamaría, Z.; García-Fraile, P. Genome Analysis and Genomic Comparison of the Novel Species Arthrobacter ipsi Reveal Its Potential Protective Role in Its Bark Beetle Host. Microb. Ecol. 2021, 81, 471-482. [CrossRef] [PubMed] 